\title{
La descripción disciplinaria en Martín Rivas y El ideal de un Calavera de Alberto Blest Gana*
}

\author{
The disciplinary description in Martin Rivas and \\ El ideal de un Calavera by Alberto Blest Gana
}

\section{Horacio Simunovic Díaz}

Universidad Católica de la Santísima Concepción. Concepción, Chile hsimunovic@ucsc.cl

\author{
José Manuel Rodríguez Angulo \\ Universidad de La Frontera. Temuco, Chile \\ jrodriguez@ufro.cl
}

\section{Mario Rodríguez Fernández}

Universidad de Concepción. Concepción, Chile

mariorod@udec.cl

\section{RESUMEN}

El realismo literario es un estilo de discurso rastreable a través de diversos rasgos formales, todos ellos organizados retóricamente para la producción de un efecto de lectura. Dentro de la narrativa chilena del siglo XIX, Alberto Blest Gana tiene un lugar privilegiado y sus obras han alcanzado enorme difusión a través del tiempo. Este artículo plantea una lectura del verosímil realista de dos de sus novelas: Martín Rivas y El ideal de un Calavera, desde una perspectiva crítica atenta a la configuración ideológica de los personajes y de la realidad, a través del discurso descriptivo como elemento organizador del mundo narrado. Se hace un vínculo entre estas novelas y

* Este trabajo forma parte de las actividades de investigación del proyecto Fondecyt Regular $\mathrm{N}^{\circ}$ 1121091 "De la 'aceptación' a la resistencia: una anatomía del detalle disciplinario en la narrativa latinoamericana de los siglos XIX y XX”. 
el realismo como manifestación de la ideología disciplinaria (Foucault, panoptismo) y de la culpa como significado inducido en los "sujetos disciplinados" (Starobinski).

Palabras clave: Descripción, panóptico, disciplina, realismo.

\section{ABSTRACT}

The literary realism is a style of speech traceable through various formal features, all of them rhetorically organized to produce an effect of reading. Within the narrative nineteenth century, Chilean Alberto Blest Gana has a privileged site, and his work has reached enormous popularity over time. This article is a critical reading of two of his novels: Martin Rivas and El ideal de un Calavera, from a critical perspective attentive to the ideological configuration of the characters and reality, through descriptive discourse as an organizer of the world narrated. It is a link between these novels and realism as a manifestation of disciplinary ideology (Foucault, panopticism) and guilt as an induced meaning "subjects disciplined" (Starobinski).

Keywords: Description, panopticism, discipline, realism.

Recibido: 04.03.2013. Aceptado: 09.10.2013.

\section{INTRODUCCIÓN: EL EFECTO REALISTA}

- ste trabajo observa la literatura como una práctica social posibilitada por

Cla articulación de sistemas de opciones en permanente reestructuración (propiedad que comparte con la gran mayoría de los discursos, aunque a través de condiciones pragmáticas diferentes); por lo tanto, su constitución no depende de las propiedades esenciales de un léxico determinado o de una forma especial de usar la lengua entendida como código ${ }^{1}$, considerado de manera independiente de su contexto de uso, sino al contrario, se propone la comprensión del discurso literario como una práctica social asociada a un conjunto de tipos de textos o géneros discursivos literarios, cuya producción y recepción se rigen por un sistema dinámico e inestable de convenciones de construcción de significados y fórmulas, a su vez, convencionales, de interpretación.

En el conjunto de obras literarias comprendidas usualmente dentro del

\footnotetext{
${ }^{1}$ Se habla, en este punto, de código en el sentido habitual de corpus léxico-sintáctico, conjunto de ítemes y de reglas de combinación.
} 
paradigma estético del realismo literario -haciendo caso omiso, por el momento, de las diferencias formales, ideológicas, epocales y locales de sus diversas manifestaciones históricas-, se pueden comprobar variadas técnicas o estrategias novelísticas que inducen su reconocimiento dentro de dicho paradigma: el uso de una retórica despojada de amaneramientos sentimentales, predominio del modo delocutivo (tercera persona), preferencia por temáticas cotidianas y sociales -el individuo está inserto en un medio social y su naturaleza depende de su relación con ese medio-, uso minucioso de la descripción de ambientes, personajes y situaciones, etc.

Si se considera una visión puramente formal, como la que parecen sugerir las características antes nombradas, puede perderse de vista el hecho de que cada una de ellas es en realidad un rasgo en la configuración interpretativa del discurso literario al que se adjudican dichas particularidades. Son más bien los gestos de lectura los que se comprueban en tales adjudicaciones y éstos responden a los modelos culturales de representación y co-representación generados en la dinámica entre la producción y la recepción del texto. El texto realista actualiza un patrón de lectura existente en la cultura de la comunidad de consumo en que circula de manera más o menos prototípica y a la vez nutre dicho patrón, sosteniéndolo, extendiéndolo o reformulándolo. Justamente, a propósito del discurso descriptivo, Riffaterre (1981) confirma: "The grammaticality of descriptive discourse is thus defined by its acceptability within the context of the sociolect, since the sociolect reflects a customary consensus on what reality is".

Los recursos lingüísticos se proyectan como un repertorio de opciones de construcción de significado que la lengua ofrece para servir los propósitos comunicativos más o menos complejos de los usuarios de una variedad lingüística social, epocal y culturalmente determinada. Para el caso de los usos literarios, el fenómeno no es distinto, en términos globales. La lengua se usa literariamente para resolver propósitos específicos de la práctica social literaria, en la que se organizan funcionalmente un gran número de agentes sociales: escritores, editores, lectores, profesores, alumnos, críticos, libreros, burócratas, etc. De esta manera, los determinantes del imaginario literario que habilita una clasificación histórica o estilística como la de "realismo literario" poseen una naturaleza heterogénea y situada, mientras que el sistema de convenciones que permite las categorizaciones y las organiza en redes semánticas es dinámico e inestable.

El realismo propuesto no es uno ajustado únicamente a la "intención" del autor, a su propuesta ético-estética o, tampoco, a las propiedades supuestamente invariables de un conjunto de textos. Se trata de un acercamiento 
a ciertos elementos -las descripciones en general y las "irrelevantes", dentro de ellas- que han sido comprendidos como típicos de los textos de verosímil realista, desde una perspectiva más cercana al destinatario y la cultura lectora de los textos, a lo que Villanueva (2004) llama "el principio de cooperación realista" consistente en algo así como la aceptación, por parte del lector, de los parámetros de reconocimiento de realidad en unos términos considerados tácitamente como "realistas", sin que ello signifique, de ninguna manera, un código estable y transhistórico de interpretación.

\section{BLEST GANA NOVELISTA}

Hay quienes ven en Alberto Blest Gana al auténtico "padre de la novela chilena”. Délano (1968) afirma que no se le podría disputar tal paternidad. Gonzalo Drago (1980) también considera atinada la adjudicación, a la par que considera inconcebible el olvido en que cayeron sus restos en el cementerio de París.

El uso de la descripción en la novela El ideal de un Calavera (1863) de Blest Gana presenta ciertas características observables también en otras obras del autor. Su influencia balzaciana ${ }^{2}$ lo lleva a pretender, como el modelo francés, a "pintar" un cuadro lo más completo posible de la sociedad chilena de su época. Hosiasson (2009) propone, inclusive, un conjunto de influencias realista más amplio para el novelista chileno:

La fórmula balzaciana norteó de hecho un estilo descriptivo y una temática de lo cotidiano, combinados con digresiones moralizantes, colocando en evidencia el modo cómo las relaciones sociales y amorosas se pautan por intereses predominantemente económicos. Pero también fueron incorporados los cuadros descriptivos a la Dickens y el realismo de Stendhal, el historicismo de Scott y el naturalismo de Zola.

La novela El ideal de un Calavera fue publicada un año después que Martín Rivas. Ambas son referentes privilegiados de la novelística de Alberto Blest Gana y guardan entre sí una serie de semejanzas estilísticas, pero también existen diferencias; por ejemplo, en el grado de atracción que el narra-

\footnotetext{
${ }^{2}$ Blest Gana confiesa el influjo de Balzac en su obra y hay un acuerdo general de la crítica en reconocer esa filiación. Hernán Díaz Arrieta (Alone), en su prólogo al tomo I de las Obras selectas de Blest Gana, publicadas por El Ateneo, se refiere al chileno de la siguiente manera: "En América, Honorato de Balzac tuvo un hijo directo, de filiación indiscutible, declarada por el propio interesado, cuya obra no se comprendería y acaso no hubiera existido sin el influjo del maestro" (Blest Gana, 1970: xi).
} 
dor se permite mostrar por la figura antiheroica de Abelardo Manríquez, el protagonista de El ideal de un Calavera, que en la novela anterior tendría su símil en la figura del personaje de Rafael San Luis.

Jaime Concha (1977), en el prólogo que hace a Martín Rivas, había destacado ya el desdoblamiento de la figura burguesa en dos facetas: la del rebelde heroico, por un lado, y la del burgués conservador, por otro. Concha afirma que en las novelas de Blest Gana el segundo sobrevive mientras que el primero es sacrificado: “...una historia que ha exigido la muerte de uno para el triunfo confortable y prosaico del otro...” (Concha, 1977: XIX).

Sin embargo, los personajes no sólo se construyen en el desarrollo de las novelas a través de descripciones. Sus acciones configuran también la comprensión que se tiene de ellos en la lectura. En el caso de las novelas estudiadas, resulta significativo ver la tensión existente entre las descripciones de los personajes y las acciones que llevan a cabo.

En las páginas siguientes se propone una lectura de dos novelas chilenas clasificadas generalmente como realistas por la crítica $^{3}$ y que poseen un lugar destacado dentro de la historia literaria nacional, así como en la constitución de los repertorios del canon literario chileno. Las novelas El ideal de un Calavera y Martín Rivas son estudiadas desde una perspectiva crítico-discursiva con el fin de caracterizar y explicar el funcionamiento de la descripción en el contexto general de la organización ideológica de la novela.

Para ello se plantea una interpretación de las funcionalidades discursivas del género descriptivo, a la vez que se rastrea su presencia en las novelas estudiadas, con especial interés en las descripciones aparentemente anodinas e irrelevantes. El objetivo del estudio consiste en mostrar la funcionalidad ideológica de dichas estructuras textuales y su importancia inaparente por constituir elementos de construcción suntuaria, supuestamente decorativa.

El método del estudio consiste en hacer un análisis lingüístico-discursivo y narratológico de las descripciones en las novelas Martín Rivas y El ideal de un Calavera, para luego someterlas a una interpretación basada en las ideas de Michel Foucault sobre la sociedad disciplinaria y el ejercicio microfísico del poder, avalados por las formaciones discursivas como dispositivos macro y micropanópticos de control. En una fase intermedia a los dos momentos mencionados, el artículo hace una reflexión analógica entre los planteamientos de Starobinski respecto a la personalidad cultural paradójica de Jean Jacques Rousseau, por un lado, y los rasgos de represión y control

${ }^{3}$ Araya (1975) ve un predominio absoluto del plan realista en Martín Rivas: "Novela realista en todos sus aspectos, incluso en los elementos románticos que se han filtrado en ella, como ocurre con otras obras del mismo género". 
micropolítico expresados en ciertos dispositivos textuales de las novelas estudiadas, por otro.

\section{EL GÉNERO DESCRIPTIVO Y SU MULTIFUNCIONALIDAD}

El género descriptivo ha sido poco estudiado y, generalmente, de forma secundaria o subsidiaria respecto de otros géneros discursivos más prestigiosos o protagónicos. La descripción es un tipo de construcción textual, un tipo de discurso, el propósito operativo de un texto o un fragmento funcional de la textura.

Una definición clásica es la de Fontanier (Pimentel, 2001: 17) "La Descripción en general (...) consiste en poner un objeto a la vista, y darlo a conocer por medio de los detalles de todas las circunstancias más interesantes, lo cual da pie a la Hipotiposis cuando la exposición del objeto es tan vívida, tan enérgica, que de ella resulta, estilísticamente hablando, una imagen, un cuadro". La descripción es un discurso que vuelve disponibles por el lenguaje los objetos, los seres y los espacios referidos. Similar definición dio mucho antes Quintiliano a lo que llamó evidentia: "descripción viva y detallada de un objeto mediante la enumeración de sus particularidades sensibles" (Pimentel, 2001: 17). La visibilidad de las entidades es algo común a la mayoría de las definiciones y la introspección de lo visible es el efecto esperable de la lectura.

Lukács (1966) define dos modos distintos de presentar lo descriptivo: como "cuadro añadido" a la narración o como "punto crítico de tensión dramática". En el primer caso, se trata de un despliegue indicial de la información; en el segundo, la descripción se funcionaliza de manera distinta ya que se convierte en "ingrediente" dramático de un evento neurálgico del desarrollo de la trama.

Los textos descriptivos se caracterizan por su construcción en secuencias declarativas de naturaleza predominantemente nominal, aunque existen también otros recursos gramaticales para describir. Discursivamente, se puede plantear una semiótica informativa especial. Para Oyanedel (2005), en la secuencia descriptiva "el hablante/escritor construye, desde un punto de vista determinado, una representación de un estado de mundo (objetos, espacios, conceptos, acciones...). Para ello pone en juego determinadas operaciones cognitivas (anclaje, aspectualización por partes y cualidades, puesta en relación, tematización,...), y determinadas estrategias (clasificación, definición, analogía, comparación,...)”. La capacidad evocativa y acumulativa 
de lo "real ausente" (Pimentel, 2001) a través del lenguaje es una confianza implícita en estas definiciones.

La descripción es, entonces, un recurso de espacialización en la diégesis narrativa, pero también lo es de identificación. La referencialidad del lenguaje descriptivo hace de las estructuras que lo realizan un conjunto de estrategias discursivas de función icónica estabilizadora y promueven la coherencia del texto. Greimas asegura que, en semiótica literaria, "la iconicidad encuentra su equivalente bajo el nombre de ilusión referencial' (Pimentel, 2010: 30). Según el semiótico francés, la iconización juega un papel muy importante en la figurativización del discurso, en la que los temas se convierten en figuras y posteriormente, a ellas, se les asignan atributos particularizantes, susceptibles de producir la ilusión referencial (Pimentel, 2010: 30).

El repertorio léxico y de expresiones que realiza esta función, propia de la descripción, es bastante amplio. Los nombres comunes ofrecen al lector una serie de referentes reconocibles con los cuales poblar el espacio reconocido en la lectura del texto narrativo, pero junto a ellos los adjetivos referentes a formas (redondo, cuadrado), a tamaño (grande, pequeño, ancho), colores (azul, verde, rosáceo), texturas (áspero, suave), cantidad (dos personas, algunos invitados). Un rol individualizador especial cumplen los nombres propios; entre ellos, los ficticios muestran la particularidad de los seres de la ficción y su referencialidad surge con el texto y remite al texto. Los nombres propios de referente no-ficticio - personajes históricos, pero sobre todo lugares y épocas- cumplen una función muy activa en el efecto de verosimilitud del texto ya que vuelve localizable la acción, reconocible la espacialidad y solidaria la "experiencia" de los personajes. Pero además, este espacio reconocido (o reconocible) por el lector toma la forma de un espacio modelizado ${ }^{4}$ por y para el texto, ya que deviene un espacio ideológicamente orientado (Pimentel, 2010: 31).

Este trabajo no realiza un estudio exhaustivo de todas las descripciones de las dos novelas investigadas, sino que se revisan sobre todo aquellas en que se expresan aspectos aparentemente superfluos o de menor importancia temá-

\footnotetext{
${ }^{4}$ Estos planteamientos concuerdan con Lotman (1982), quien considera la literatura -y el arte, en general- como un sistema de modelización secundario. Parece adecuado ver que la literatura remodelice, según nuevos parámetros, aquello que en el uso cotidiano de la lengua ya aparece modelizado de manera primaria; sin embargo, este trabajo no comparte los planteamientos del autor ruso, aparecidos en el mismo texto, sobre la existencia de un lenguaje literario específico o especial; antes bien, se considera que la literatura refuncionaliza la lengua en sus distintas variantes sociales de uso para efectos de una "construcción de realidad" que intenta plantearse siempre en una relación polémica respecto a la realidad -también construida socialmente- en que va a circular y consumirse de una determinada manera (por ejemplo, como texto literario) el texto en cuestión.
} 
tica para el desarrollo de la historia narrada en la novela, pero que muestran señales del sistema evaluativo del texto. La construcción de los personajes principales no se realiza sólo a partir de sus principales descripciones y la narración de sus principales acciones, sino también a través de datos aparentemente menores. Esta proliferación del detalle nimio tiene funciones de diferente naturaleza, puesto que mientras los detalles contribuyen a nutrir informativamente la configuración de realidad propuesta por la novela, al mismo tiempo delinean la interpretación valórica propuesta en el texto para esa realidad "levantada" desde el lenguaje. El grado de su "insignificancia" se mide por su relación con los avatares de la acción o por su capacidad para definir las identidades agenciales, locales o instrumentales; sin embargo, tienen normalmente una relación directa con la perspectiva ideológica con que el narrador realiza la disposición estética general de la obra en su proceso de producción y controla las posibles desviaciones de la lectura.

Barthes, en un interesante artículo sobre la relación entre los "detalles superfluos" y el "efecto de realidad", desarrolla una teoría del verosímil realista como matriz opuesta al verosímil antiguo en que "lo real" estaba del lado de la Historia y "lo verosímil", lo imitativo, del lado de la poesía (la literatura). Barthes propone una "ruptura entre lo verosímil antiguo y el realismo moderno" (1972: 100). El autor plantea que es "lo real" y no sus significados contingentes lo que se significa. Lo que caracterizaría al realismo es una carencia del significado en provecho del referente, “...se produce un efecto de realidad fundamento de ese verosímil inconfesado que constituye la estética de todas las obras corrientes de la modernidad" (Barthes, 1972: 100).

\section{EL OJO VIVO DE LA CULPA}

Jean Starobinski dice que Rousseau sólo se atrevió a desear en secreto. Rousseau habría desarrollado una especie de "paranoia" o principio de anticipación de lo que los otros piensan de él o podrían pensar de él. Le importa y angustia demasiado la imagen que tienen de él los demás y ha decidido "no desear", puesto que el deseo y la codicia le parecen insoportablemente vergonzosos. Sin embargo, según Starobinski, Rousseau habría descifrado qué es lo que piensan los demás de él. La angustiante incertidumbre debía ser resuelta. En el lugar de las posibilidades cambiantes e imprecisas de la imagen que se hacen de él los otros, se ha instalado una cruel claridad, un juicio sobre el que no hay apelación.

La hostilidad es un precedente que todo lo envenena, por lo tanto, los 
gestos de Rousseau no son ya primigenios sino réplicas. Elimina, de esta manera, la incertidumbre y la ambigüedad e instala en el centro de sus ideas la derrota antes de que la batalla comience (Starobinski, 1989: 14-16). Starobinski habla de una "economía del sufrimiento". Es mejor ser el blanco de la hostilidad de los otros que sufrir los embates del tormento interno. La discordia externa es el precio a pagar por la disminución del sufrimiento íntimo (Starobinski, 1989: 14-16).

Estudioso de la melancolía, Starobinski elabora una crítica de la obra y personalidad de Jean-Jacques Rousseau desde la perspectiva de la visibilidad del deseo, propiedad que lo vuelve sujeto de vergüenza y hostilidad. Una relación paradójica con el deseo de análogas características podría observarse en Blest Gana si tomamos en cuenta la construcción de sus héroes novelísticos.

Alberto Blest Gana, en la dedicatoria de su novela Martín Rivas, dirigida a Manuel Antonio Matta, evalúa a su personaje de la siguiente manera:

...su protagonista ofrece el tipo, digno de imitarse, de los que consagran un culto inalterable a las nobles virtudes del corazón, y, finalmente, mi amistad quiere aprovechar esta ocasión de darte un testimonio de que al cariño nacido en la infancia se une ahora el profundo aprecio que inspiran la hidalguía y el patriotismo puestos al servicio de una buena causa con entero desinterés (Blest Gana, 1977: 299).

Sin embargo, Martín Rivas es un personaje construido de tal forma que parece vivir la misma angustia y vergüenza que Starobinski atribuye a Rousseau: "El modo como aquel joven se acercó a un criado que se balanceaba, mirándole, apoyado en el umbral de una puerta que daba al primer patio, manifestaba también la timidez del que penetra en un lugar desconocido y recela de la acogida que le espera" (Blest Gana, 1977: 301). Se trata de un personaje avergonzado de su condición, que desea trascender sus limitaciones sociales. Está recién llegado a la capital y su miedo es sólo comparable a su orgullo. "Martín se había quedado en el mismo lugar en que se detuvo para hablar con el criado, y dejó pasar dos minutos sin moverse, contemplando las paredes del patio pintadas al óleo y las ventanas que ostentaban sus molduras doradas a través de las vidrieras" (Blest Gana, 1977: 302).

El personaje se debate íntimamente intentando exteriorizar y ofrecer a la vista lo menos posible. Starobinski escribe sobre esta percepción del cuerpo propio a la que llama "cenestesia": "que constituye, sin duda alguna, un 
componente de la 'sensibilidad' contemporánea, tanto entre los filósofos, como entre los escritores, en ciertas prácticas psicoterapéuticas (el 'training autógeno' de Schulz, la relajación, los 'abordajes corporales'), o finalmente en la reflexión psicoanalítica" (Starobinski, 1981: 261-262).

En esta conciencia íntima del cuerpo existe también una relación con el otro. Relación problemática de la que se deriva este "pudor melancólico" que lleva a veces al sujeto al enmascaramiento y la simulación, a intentar pasar por otro. Starobinski ve en Rousseau esta doble naturaleza, paradójica, de intentar aparecer visible a través de un conjunto de roles seleccionados y estereotípicos como el de pensador político, legislador, pedagogo y, por otro lado, como el personaje librepensador y libertario. Se da un desdoblamiento entre unos personajes complementarios creados para la visibilización externa.

El pudor se transforma en un método de aprendizaje y la vergüenza en una herramienta provechosa, mientras no da señales externas. Martín Rivas aprende a ser un burgués y a codearse con la sociedad capitalina producto de la conciliación entre su puritanismo intrínseco y el manejo entrenado de la escisión entre imagen pública e interioridad o sentimientos.

La idea de la melancolía aparece vinculada en Starobinski a la escritura. A una especie de descentramiento o alienación del sujeto de su propia experiencia íntima. Una suspensión de la identidad del sujeto producto de la presencia de otro sujeto, el del texto. Él mismo destaca en entrevista realizada por Carmelo Colangelo que la melancolía ha sido asociada desde tiempos remotos a los espíritus excepcionales: hombres de guerra, políticos, héroes. "Habría, de este modo, una fuente somática capaz de alimentar, por su variabilidad y su carácter peligroso, los grandes vuelos del espíritu, y esto al precio de unos momentos más difíciles, letárgicos, de pérdida del dominio de las capacidades interiores. De ahí esa irregularidad del hombre melancólico que ya se había advertido en el pasado" (Starobinski, 1991). Como indica también el autor ginebrino, sólo hacia el siglo XVII la melancolía empieza a asociarse con el acto literario y la contemplación.

Esta separación del mundo externo puede verse no sólo en algunos aspectos de la vida social del autor Alberto Blest Gana, sino también en la configuración problemática y compleja de sus personajes y la relación que el narrador establece con ellos.

Hosiasson (2009) destaca, como ya había hecho Concha, que se trata de dos novelas concebidas en el lapso de dos años que tienen como trasfondo la derrota del liberalismo político frente al conservadurismo y desarrolladas en el período inmediatamente anterior a su largo autoexilio europeo. La 
autora pone en contraste al personaje protagónico de Martín Rivas con el de El ideal de un Calavera. Ve una diferencia fundamental entre "el recatado Martín” y "un antihéroe típicamente romántico y exuberante" como el de la siguiente novela.

La inestable postura moral del sujeto íntimo en el personaje Martín Rivas contrasta con la impetuosidad de Abelardo Manríquez el protagonista de El ideal de un Calavera. Martín Rivas experimenta una verdadera odisea moral, plagada de inseguridades, malentendidos y aprendizajes tortuosos que lo proyectan en un ser intrínsecamente débil, quien sólo descubre estadios de fortaleza anímica con el tiempo y la experiencia, pero sobre todo con la tranquilidad emocional derivada de su reconocimiento del amor correspondido por Leonor.

Su volubilidad anímica queda claramente descrita en el pasaje de su encarcelamiento, en los capítulos finales de la novela:

El joven se sentó sobre los ladrillos, apoyó la espalda en la pared y cruzó los brazos sobre el pecho. En esta actitud, bajó la frente, cual si el peso de las ideas que a su cerebro se agolpaban le impidiese mantenerla erguida como al entrar al calabozo (...) La belleza de Leonor, su apasionado lenguaje, su interés cariñoso, la profunda tristeza de la última mirada, brillaron a un tiempo en la mirada de Rivas, hicieron latir su corazón y poblaron la desnuda prisión con las rosadas y lucientes imágenes que como de un foco luminoso irradian del alma enamorada.

Al ver la apasionada expresión del rostro de Martín, cuyos ojos vagaban en el espacio, hubiérase dicho que aquel joven, encerrado en un miserable cuarto, soñaba con la conquista de un imperio.

Mas pronto la imaginación inquieta pidió a la memoria otros recuerdos y huyó aquella alegría de las facciones del prisionero; llenóse de suspiros su pecho, y, como ahogado por el pesar, se puso de pie y se acercó a la ventana. Sus labios dejaron escaparse con profundo pesar estas palabras: -¡Pobre Rafael! (Blest Gana, 1977: 348).

El personaje se debate entre una serie de cambios de estado anímico sucesivos y su fragilidad sólo se relativiza cuando asoma la esperanza de lograr su reunión con Leonor. "Si yo hubiese sido menos orgulloso, habría sabido antes que Leonor me amaba y no estaría ahora aquí, sino a su lado" (349).

Román Soto, en su estudio de la construcción del héroe en Martín Rivas, opina: "El héroe de Blest Gana queda definido por un eficaz saber actuar y por el reconocimiento por el que finalmente la tertulia lo recibe en su salón. 
La eficacia es condición para su reconocimiento e, inversamente, su actuación es eficaz en tanto genera tal reconocimiento" (Soto, 1992: 35). Para Soto, Martín Rivas queda integrado a la tertulia y este evento lo afirma en su estaticidad. En cuanto novela de pruebas, le permite recuperar, pasados los obstáculos, la imagen armónica del mundo y le permite integrarse en él de forma dócil (1992: 35). El personaje es disciplinado en su contacto inteligente con las pruebas que le ha hecho pasar el nuevo mundo al que desea integrarse.

Al contrario, Abelardo Manríquez es un personaje que no trepida y sigue sus impulsos hasta las últimas consecuencias: 'Los hombres organizados como Abelardo Manríquez son esclavos de un señor imperioso que manda con la ley antojadiza del capricho: ese señor despótico es el corazón" (Blest Gana, 1970: 672) El protagonista de El ideal... se ve afectado por el mundo, no se disciplina y finalmente sucumbe bajo su influjo.

La forma ambivalente en que Blest Gana construye a sus personajes rebeldes hace pensar en la proyección de una angustia similar a la que Starobinski plantea en Rousseau. La diferencia estaría en que Blest Gana reserva para sus personajes la angustia que podría provocarle el paradójico desarrollo de la "conciencia nacional" respecto a la vida en general o a la vida social y política en particular. Es el advenimiento de la "mala conciencia" de la culpa provocada por la irresolución de los conflictos más elementales: conservador o liberal, realista o romántico, espíritu o materia.

\section{SER VIGILADO Y CASTIGADO: EL PANOPTISMO NOVELESCO}

Michel Foucault despliega una interpretación de la modernidad como un programa de disciplinamiento social que modifica la antigua práctica del castigo físico y público por un sistema de castigo del "alma" y de carácter privado. Los mecanismos de punición se racionalizan y deja de verse al castigo en términos de venganza. Alrededor del siglo XVIII se habría impuesto una nueva forma de relación entre lo público y lo privado.

En el mundo antiguo y medieval, las multitudes gozaban de una suerte de connivencia con el poder que les hacía accesibles, en la forma de un espectáculo, el castigo y el escarnio de los delincuentes. La vergüenza de la exposición y el suplicio del cuerpo eran la médula de la lógica punitiva. En la era moderna se reorganiza esta relación invirtiendo su sentido. Unos pocos (eventualmente uno solo) tendrán acceso a la visibilidad de grandes grupos humanos. El principio de exposición se cambia por el de vigilancia 
y este sistema inherente a la modernidad se extiende de manera aun más compleja hasta nuestros días.

El ejercicio de la disciplina supone un dispositivo que coacciona por el juego de la mirada; un aparato en el que las técnicas que permiten ver inducen efectos de poder y donde, de rechazo, los medios de coerción hacen claramente visibles aquellos sobre quienes se aplican. Lentamente, en el trascurso de la época clásica, vemos construirse esos "observatorios" de la multiplicidad humana para los cuales la historia de las ciencias ha guardado tan pocos elogios. Al lado de la gran tecnología de los anteojos, de las lentes, de los haces luminosos, que forman cuerpo con la fundación de la física y de la cosmología nuevas, ha habido las pequeñas técnicas de las vigilancias múltiples y entrecruzadas, unas miradas que deben ver sin ser vistas; un arte oscuro de la luz y de lo visible ha preparado en sordina un saber nuevo sobre el hombre, a través de las técnicas para sojuzgarlo y de los procedimientos para utilizarlo (Foucault, 1988: 175-176).

Las novelas de Blest Gana son herederas del espíritu dieciochesco de lo pictórico y lo pedagógico y, al mismo tiempo, develadoras de las contradicciones y esperanzas de una sociedad en ciernes, acomplejada por el conflicto entre su raíz mestiza y sus ideales aprendidos de civilización a la europea. La óptica disciplinaria de la que nos habla Foucault se muestra en distintos niveles de organización tanto macro como micropanópticos.

Rodríguez y Triviños (2006) consideran panóptica la vigilancia ejercida por el narrador que "no se limita a disciplinar los cuerpos indóciles que circulan por el mundo novelesco, sino que alcanza a lo que parece constituir su verdadero fin: disciplinar al destinatario del mensaje, el lector" (18). El lector resulta una pieza en el mecanismo de la novela como dispositivo panóptico. Los autores recién nombrados no se refieren en particular a las novelas de Blest Gana, sino a todas las novelas, al género novela como género moderno -sobre todo la novela realista- en que el pacto enunciativo entre narrador y narratario activa dentro de la semiótica novelesca uno más externo entre autor y lector. La novela ofrece al lector la posibilidad de vigilar en detalle un mundo poblado y accesible en diferentes grados, según la exposición informativa hecha por el texto y según la disposición de vigilancia por parte del lector. Como se ha indicado antes, en la interpretación dada a las obras el papel activo del lector es determinante.

A continuación se analizan dos fragmentos de función descriptiva, uno de cada novela, para demostrar la forma cognitivamente menos "relevante" 
en que se manifiesta la estructura ideológica del texto novelesco.

El nivel micropanóptico se puede rastrear, por ejemplo, en las descripciones que nutren la narración. Tanto en las que cumplen un papel funcional perfectamente visible, como en aquéllas cuyas existencia sugiere un alarde o exceso del texto. Resultan "micropanópticas", explicado de manera simple, porque su función estratégica no sólo es menos evidente, sino porque se trata de datos desvinculados de otras funciones de valor dramático en las obras.

Véase, por ejemplo, la manera en que se construye la siguiente descripción del personaje, en el arranque de la novela Martín Rivas, y piénsese en la importancia que representa que la novela parta, justamente, con una descripción:

A principios del mes de julio de 1850 atravesaba la puerta de calle de una hermosa casa de Santiago un joven de veintidós a veintitrés años.

Su traje y sus maneras estaban muy distantes de asemejarse a las maneras y al traje de nuestros elegantes de la capital. Todo en aquel joven revelaba al provinciano que viene por primera vez a Santiago. Sus pantalones negros, embotinados por medio de anchas trabillas de becerro, a la usanza de los años de 1842 y 43; su levita de mangas cortas y angostas; su chaleco de raso negro con largos picos abiertos, formando un ángulo agudo, cuya bisectriz era la línea que marca la tapa del pantalón; su sombrero de extraña forma y sus botines abrochados sobre los tobillos por medio de cordones negros componían un traje que recordaba antiguas modas, que sólo los provincianos hacen ver de tiempo en tiempo, por las calles de la capital (Blest Gana, 1977: 5).

La primera oración-párrafo de la novela tiene una organización "marcada" nal de función circunstancial temporal: "A principios del mes de julio de 1850 ", se sigue con la estructura predicativa "atravesaba la puerta de calle de una hermosa casa de Santiago", para finalizar el párrafo con el sujeto oracional, pospuesto, introductorio del protagonista, quien da nombre a la obra, pero que no será "llamado" por su nombre de pila, sino posteriormente: "un

5 La distribución "no marcada" o "normal" de la oración, en castellano, sigue el orden SVO (sujeto-verbo-objeto).

${ }^{6}$ En el sentido de la estructura funcional informativa tema-rema, surgida en el contexto de los estudios lingüísticos pioneros del Círculo de Praga y que ha sido interpretada de maneras tan contradictorias como variadas por la tradición posterior. En este trabajo se asume que tema es el punto de arranque oracional, el que coincide con el punto de vista del hablante. 
joven de veintidós a veintitrés años”.

El párrafo está compuesto por una sola oración, sintácticamente invertida, lo que propicia de manera más cómoda retomar, en el próximo párrafo, el referente sin volver a nombrarlo nominalmente en términos identificativos.

En el párrafo siguiente se continúa hablando del personaje, aún sin nombrarlo por su nombre, a través de una alusión sinecdóquica de sus "partes" sociocorporales (el traje) y sociosemióticas (sus maneras). De inmediato, la descripción adquiere sentido comparativo: "Su traje y sus maneras estaban muy distantes de asemejarse a las maneras y al traje de nuestros elegantes de la capital". Es vistoso cómo se describe al personaje en este pasaje, a partir de su aspecto y de la impresión provocada en quien "lo ve"; en este caso los habitantes de la casa santiaguina a la que va llegando, pero también el lector que comparte la visión inaugural del personaje. Primero a través de su edad estimada, "veintidós a veintitrés años", y luego mediante su presentación social: su traje y maneras. Tanto la vestimenta como los modales son comparados con los de "nuestros elegantes de la capital". Comentario clasista de filiación por parte del narrador, indiscreción de clase, diríase, tomando en cuenta que para emitir un juicio como ese es necesario primero conocer a los elegantes capitalinos y luego verlos y frecuentarlos, seguramente, como iguales y que proyecta, por solidaridad prometida, una imagen de la construcción figural del lector inscrito en el texto: uno que como el narrador reconozca a los miembros de las clases elegantes, sus vestimentas habituales y sus maneras sociales. Es muy claro el gesto de complicidad narrador-lector que se marca en el uso del posesivo "nuestro", integrador de narrador y lectores en una misma colectividad ideal.

El lector vigila la diégesis novelesca, mientras el narrador vigila a sus personajes y al lector. No se trata de una relación desaprehensiva entre el narrador de las novelas de Blest Gana y sus lectores, el espíritu interpretativo de la "pintura" que el narrador hace de la realidad es suficientemente fuerte para presentarnos, "en persona”, al personaje en estas primeras páginas.

También es digno de destacarse en esta misma estructura, la fórmula estilística cortés con que se establece la diferencia entre el provinciano y los capitalinos. En vez de usar una estructura comparativa más habitual como "su traje y sus maneras son distintos a..." o "su traje y sus maneras eran menos sofisticadas..." o "su traje y maneras eran más rústicos", etc. Se usa

7 La sinécdoque es la figura retórica que forma parte de los llamados tropos de dicción (metasememas) basada "en la relación que media entre un todo y sus partes" (Lausberg, en Beristáin, 1995: 464). 
una estructura de atenuación e indirecta: "su traje y manera estaban muy distantes". Este aspecto de la descripción proyecta al narrador como un coanfitrión del personaje en el ambiente al que se asoma como advenedizo y lo sitúa en una posición evaluadora, acorde con el rango autoasumido y con la centralidad que tendrá el personaje en la estructura de la novela. Posición que ha hecho ver a Martín Rivas como novela de aprendizaje ${ }^{8}$; en este caso, Martín Rivas vive un proceso de evolución de la mano de un narrador que no renuncia a evaluar las etapas de dicho proceso.

La entrada a la visibilidad del personaje continúa de la siguiente manera: "Sus pantalones negros, embotinados por medio de anchas trabillas de becerro, a la usanza de los años de 1842 y 43; su levita de mangas cortas y angostas; su chaleco de raso negro con largos picos abiertos, formando un ángulo agudo, cuya bisectriz era la línea que marca la tapa del pantalón; su sombrero de extraña forma y sus botines abrochados sobre los tobillos por medio de cordones negros componían un traje que recordaba antiguas modas, que sólo los provincianos hacen ver de tiempo en tiempo, por las calles de la capital". Toda esta parte de la descripción compone una sola unidad, en que con la mirada detallista y crítica del chismoso o el alcahuete, desarrolla una radiografía geosocial del personaje, reconocido entonces como provinciano pobre, un rústico sin roce social, sin dinero, miembro de una clase vasta y detectada por la élite local.

Un detalle importante está en el hecho de que el narrador utilice una referencia histórica muy precisa a la moda de los años 1942 y 43, en una maniobra de periodizador de la moda, de individuo que está al tanto de la moda como dato histórico-cultural objetivo. Esto vuelve esta descripción muy "actual", en el sentido "ultimista" de la palabra. La moda referida tiene como contraparte referencial un "estado de la moda actual" que no aparece descrito, pero que el lector coetáneo y enterado debiera reconocer por contraste.

El detalle geométrico de esta descripción también es significativo desde el momento en que el sujeto de elegancia (o de posible elegancia) emerge como un paquete organizado en todas sus partes componentes de manera minuciosa y estudiada, sólo que la forma afectivamente distante en que se describe la indumentaria de Martín hace sentir al lector el "desprecio" del narrador por el arreglo.

La disciplina no asoma ya en la manera en que el narrador adoctrina abiertamente al lector para controlar su interpretación por medio de inter-

\footnotetext{
${ }^{8}$ Ver Jaime Concha (1972).
} 
pelaciones directas o a través de una historia que por sus episodios revelen una comprensión disciplinar de la realidad -aunque en el caso de estas dos novelas, también se da de esa forma-, sino que se realiza por la intercalación de abundamientos informativos, aparentemente inocuos, que consagran una visibilidad de los seres y los espacios, a la vez que una interpretación de sus cualidades principales, de tal manera que resultan menos evidentes sus efectos.

La extensa descripción que sigue muestra la manera en que el género descriptivo despliega la ideología -en cuanto sistema de valores culturales organizador del sistema de significados sociales- del narrador de Martín Rivas:

Magnífico cuadro formaba aquel lujo a la belleza de Leonor, la hija predilecta de don Dámaso y de doña Engracia. Cualquiera que hubiera visto aquella niña de diecinueve años en una pobre habitación habría acusado de caprichosa a la suerte por no haber dado a tanta hermosura un marco correspondiente. Así es que al verla reclinada sobre un magnífico sofá forrado en brocatel celeste, al mirar reproducida su imagen en un lindo espejo al estilo de la Edad Media, y al observar su pie, de una pequeñez admirable, rozarse descuidado sobre una alfombra finísima, el mismo observador habría admirado la prodigalidad de la naturaleza en tal feliz acuerdo con los favores del destino. Leonor resplandecía rodeada de ese lujo como un brillante entre el oro y pedrerías de un rico aderezo. El color un poco moreno de su cutis y la fuerza de expresión de sus grandes ojos verdes, guarnecidos de largas pestañas; los labios húmedos y rosados, la frente pequeña, limitada por abundantes y bien plantados cabellos negros; las arqueadas cejas, y los dientes, para los cuales parecía hecha a propósito la comparación tan usada con las perlas; todas sus facciones, en fin, con el óvalo delicado de su rostro, formaban en conjunto una belleza ideal, de las que hacen bullir la imaginación de los jóvenes y revivir el cuadro de pasadas dichas en la de los viejos (Blest Gana, 1977: 11).

La descripción está plagada de elementos evaluativos respecto a lo descrito que permiten comprender el sistema de valores en juego, con respecto a uno de los personajes más importantes de la novela y respecto al espacio en el que se integrará finalmente el protagonista.

En primer lugar, la escena por describir es catalogada por el narrador como un cuadro "magnífico" de lujo circundante (y concordante) a la belleza de Leonor. El narrador define su labor, por lo tanto, como la de un pintor retratista, para acentuar el efecto visual de la escena. Lo siguiente es una ape- 
lación al sentido común del lector "Cualquiera que hubiera visto...”. El uso del subjuntivo presenta esta fase de la descripción como una hipótesis, una conjetura sostenida en base a la complicidad del lector, a través del sentido común. La combinación con el uso del condicional "habría acusado de caprichosa a la suerte" respalda y extiende la conjetura a la reacción del hipotético observador de tan injusta escena conjetural. Sin embargo, esta fase sólo tiene la función de resaltar la fase descriptiva siguiente, todavía enganchada a la conjetura anterior, para mostrar la posibilidad de que el mismo imaginario observador hubiera contemplado la opulenta (tan coherente como justa) escena real: "Así es que al verla reclinada sobre un magnífico sofá forrado en brocatel celeste (...) habría admirado la prodigalidad de la naturaleza en tal feliz acuerdo con los favores del destino".

La fase siguiente es de plena "realidad". Se ha abandonado el discurso hipotético introductorio. El uso del pretérito imperfecto de indicativo vuelve al lector a la realidad de la escena. Resulta evidente la satisfacción del narrador por la coherencia entre el lujo contextual y la belleza del personaje. La descripción física de los rasgos definitorios del ideal de belleza encarnado en Leonor muestra, nuevamente, la confianza en la complicidad del lector, quien debiera confirmar que la idealidad de la belleza del personaje es real, a pesar de ser ideal. Para lograr dicho efecto, los significados construidos por el lenguaje deben ser reconocidos en su valor estético-ideológico y compartidos por reconocimiento.

El narrador se da el lujo de referir, metaliterariamente, al hecho de que la comparación que va a usar de los dientes perfectos del personaje con perlas es una expresión común, un cliché, como la mayor parte de la descripción, sin que confiese sobre su totalidad tal reconocimiento.

Por último, en la fase de resolución de la descripción, alude al espectro amplio de los miembros masculinos de la sociedad al hablar del efecto estimulante que produciría en la imaginación de los jóvenes y nostálgico en los viejos la belleza de Leonor. Existe, evidentemente, un sesgo clasista y moralizante al no imaginar ninguna otra reacción posible, ni la plausibilidad de que el observador fuese de otra clase social, otra condición mental, entre otras posibles condiciones.

Las siguientes son descripciones de la novela El ideal de un Calavera, que en muchos aspectos continúa una estética y en otros la modifica. Mientras Martín Rivas es una novela de ambientación fundamentalmente urbana, El ideal... transita distintos ambientes: campo y ciudad, capital y provincia. Por otra parte, también es muy diferente el tipo de héroe protagónico, como 
se dijo más atrás. El compuesto Martín Rivas contrasta con el impulsivo y antojadizo Abelardo Manríquez. Sus destinos son diametralmente opuestos; sin embargo, su vínculo ideológico es con ambos. Si bien parece mostrar una atracción mayor por el personaje romántico y complejo de El ideal..., el destino que le reserva concuerda con el cuidado con que Martín logra sus objetivos en la sociedad chilena. La ideología de la novela realista, que expulsa los personajes conflictivos o perniciosos funciona de manera implacable, finalmente. De hecho, el destino fatal del personaje parece sumir en una melancolía creciente al narrador de El ideal..., que abunda en comentarios filosóficos e ideológicos de manera mucho mayor que en la novela inmediatamente anterior.

Existe un componente humorístico mucho mayor en El ideal... que en Martín Rivas. Gotschlich (1987) observa el carácter grotesco de este humor y lo vincula con la influencia romántica de Víctor Hugo, en especial la del prólogo a Cromwell. Ironía y tragicomedia confluirían en esta obra para componer un cuadro complejo de la realidad retratada y de sus personajes.

El personaje va siendo presentado de a poco, luego de que inmediatamente se nos confiesa su muerte trágica en las primeras páginas. Esta "muerte anunciada" se explica de múltiples maneras a través de la novela. Al revés de la simpleza anímica característica de las primeras caracterizaciones (por no decir todas) de Martín, en el caso de Abelardo existe una variedad nunca del todo exhaustiva y no plenamente explicada que abunda en rasgos psicológicos más que físicos y que expresan la simpatía sentida por el narrador.

El corazón de Abelardo era como esos potros que triscan por los grandes potreros, saltando y relinchando para desfogar el exorbitante vigor de la juventud. No creía hacer ningún mal mortificando a sus maestros, sino que cedía a una fuerza irresistible al ejecutar el sinnúmero de travesuras que el lenguaje de los colegios populariza con el nombre de diabluras (Blest Gana, 1970: 659).

Es otro tipo de descripción, ya que persigue otro fin. El texto anterior muestra un personaje protagónico complejo que deberá ser sacrificado y la tragedia de su destino amerita una cualificación pertinente. Parece haber una división ideológica íntima en el narrador que escoge por "ley novelesca realista" sacrificar un personaje que en realidad le atrae. La realidad lo expulsa, pero el cronista de la tragedia lo honra. No como defensa crítica de un ideal revolucionario, sino como expresión ambivalente de un deseo no consumado ni consumable en una sociedad como la chilena. 
Abelardo no era un ente vulgar. Muy poco le tentaban los bienes materiales, a los que en nuestros días se enseña a la juventud a rendir un culto fervoroso. Llevaba en su alma turbulenta por la savia de la juventud, esa chispa de aspiración vaga que sólo se anida en los pechos de aquellos que nacen organizados para distinguirse del vulgo. Esa chispa que, comunicando su ardor al cerebro, forma después los notables escritores, los sabios, los grandes guerreros y los grandes enamorados; seres cuya sensibilidad impresionable, en cierto punto de vista, les hace cruzar el mundo separados de la turba, con más dolores que los dolores comunes, y con alegrías menos espontáneas que la alegría fácil e irreflexiva de los hijos del materialismo; seres infelices que raras veces pueden contentarse con la realidad del presente: poetas del porvenir, cuando jóvenes; peregrinos del pasado, cuando la nieve les oculta las risueñas alturas de la esperanza (Blest Gana, 1970: 662).

La atracción del narrador es muy evidente. Diríase que el ideario romántico compite con su "misión" pedagógica que siempre ha de tener algo de ejemplarizadora. Sin embargo, coinciden ciertas posturas mostradas desde ambas vertientes: el desprecio por los bienes materiales, la crítica de la educación o del destino actual de la sociedad, el rechazo del vulgo y de las masas, la esperanza de lo extraordinario.

Es dable pensar que cuando el narrador dice "los notables escritores, los sabios, los grandes guerreros y los grandes enamorados; seres cuya sensibilidad impresionable, en cierto punto de vista, les hace cruzar el mundo separados de la turba, con más dolores que los dolores comunes, y con alegrías menos espontáneas que la alegría fácil e irreflexiva de los hijos del materialismo" se sienta identificado con los valores que detalla y se sienta, quizá, un "gran escritor", "un sabio" o, al menos, alguien "separado de la turba".

Descripciones como la anterior hay muchas en El ideal... y su constitución es más abierta y explícitamente ideológica que las que se vieron antes en Martín Rivas. Los detalles aparentemente inofensivos hay que buscarlos en otros objetos, en otros personajes, en algunos ambientes, más que en la vistosa figura, descrita una y otra vez, de Abelardo Manríquez.

Por ejemplo, se describe así a Inés, personaje femenino que es objeto de deseo y cortejo por parte del protagonista: "Sentada en un banco debajo del parrón, con un libro en la mano, el airoso cuerpo reclinado hacia la derecha y la espalda apoyada a un pilar. Inés miraba al frente y parecía embebida en su contemplación" (673).

La descripción de la joven es casi arquetípica, muy simple, compuesta 
únicamente de visibilidades para el protagonista y para el lector. Su ser interior se reduce a estados visibles en función del rol que juega en la acción del protagonista. "Manríquez tuvo, al divisarla, un vahído de cabeza que nubló su vista por un momento" (673). Sólo existe en la escena para justificar primero el arrobo y luego el entusiasmo de Manríquez.

¿Cómo un plan descriptivo de esta naturaleza confirma la tesis del papel micropanóptico de las descripciones, sobre todo aquellas menos "relevantes"? La tesis se confirma por contraste entre las descripciones de los distintos personajes, objetos, ambientes y situaciones. La descripción se releva así como un dispositivo organizador de los detalles de los elementos y las coordenadas de la realidad que en su conjunto ofrece la figura de un diseño, no siempre del todo homogéneo ni simple. En el caso de estas novelas de Blest Gana, se puede comprobar un diseño ideológico transtextual que reúne, en una misma alegoría de la realidad, el componente ético paradójico y sin embargo coherente, propiciado por ambas novelas.

\section{CONCLUSIONES}

La disciplina es el mecanismo de control social que se aplica de manera externa de un modo más o menos visible, a través del sistema penal y carcelario, de la educación, de los sistemas de salud y, de manera interna o introspectiva, a través de mecanismos subsidiarios como el autocontrol, el respeto privado de la ley, la ideología del trabajo y de la producción, la ética del premio al esfuerzo, la ideología de la familia, el respeto a la moral y las buenas costumbres, la naturalización del gregarismo y sus formas de distribución socioeconómica, el adoctrinamiento en el consumo capitalista, etc. Si se hace un examen de las condiciones de vida y los aparatos de coerción social, se puede ver claramente que la situación surgida en el contexto de la sociedad del siglo XVIII, lejos de modificarse en lo sustancial, ha profundizado su efecto, sofisticado y ampliado sus métodos, cubierto hasta el último bastión de resistencia, entre los que probablemente se contó en alguna época la universidad, a través de la función crítica.

El arte y la literatura no están exentos de esta realidad y en algunos casos incluso se manifiestan como extensiones del sistema de control global en que se han convertido las sociedades -hoy día entregadas como espacio mercantil bajo el marco jurídico, político, administrativo del Estado- a la vigilancia docilizante para efectos de un control total de los cuerpos de pro- 
ducción y disminuir o anular todo posible germen de rebeldía y resistencia.

La noción misma de Estado ha devenido en rótulo de espacio hiperdelimitado e hipervigilado, en concordancia con la decadente idea de nación que se le asocia, consigna ideológica para justificar la homogeneización y convencer a las muchedumbres mediante una narrativa de la "identidad" y la "pertenencia" manejadas de manera manipulatoria y explotadora.

Justamente, en este punto, las novelas de Blest Gana estudiadas se vinculan con el interés explícito del autor de constituir una literatura nacional, tal como han destacado diversos críticos (Subercaseaux, 1980; Poblete, 1999, 2000) y este proyecto, diríase cultural, se desarrolla por dos caminos integrados en la obra del novelista chileno. Por un lado, el apego a una herencia romántica vinculada a temas, y muchas veces un estilo, sentimentales'; pero por otro lado, el intento de mostrar una visión de la psicología de los personajes y de la sociedad chilena mediante una mirada histórica, en que los eventos nacionales hacen de relato paralelo de las historias privadas en que se centra la trama. En el caso de El ideal..., la historia privada se cruza con el motín de Quillota y el fusilamiento de Diego Portales.

El entrecruzamiento de ambas estéticas hace que el estilo de las descripciones sea coincidente con la ambivalencia mostrada en la construcción general de los personajes, sobre todo los protagónicos, y con la organización general del material narrativo en pos de un proyecto que integra ambas vertientes.

El aspecto realista de estas obras opera en esa conjunción de lo privado con lo histórico-público, en un bosquejo social de época que, sin embargo, perfila una sensibilidad aún romántica en la interpretación de la psiquis de los personajes, en el funcionamiento íntimo de sus pasiones, en el debate personal de su voluntad. El patetismo expresivo no resulta incongruente con la atribución de realismo a la obra de Blest Gana ya que, desde una perspectiva pragmática, el realismo más que desprenderse de un supuesto "lenguaje realista" del que se hacen eco los críticos que Villanueva llama "inmanentistas" o "realismo formal"10, se relaciona con la cointencionalidad de los interlocutores de la comunicación literaria (Villanueva, 2004: 98). El "efecto realista" resulta de la incorporación, en un mismo plan de cognición lectora, de los signos de acercamiento a una descripción de época definible, según el sentido común lector, como realista y de la descripción sentimentalista de los estados de ánimo, las acciones y los sentimientos de los persona-

${ }^{9}$ Interés que compartió junto a su hermano menor, también escritor, Guillermo.

${ }^{10}$ Desde los comentarios críticos de escritores franceses como Flaubert o Zolá, hasta los postulados del llamado Estructuralismo Francés, contenido en los trabajos de la revista Tel Quel. 
jes, heredada del paradigma literario anterior, presente todavía en el público lector como propiedades reconocibles para la comprensión de la diégesis.

Las novelas revisadas en este estudio revelan la conflictiva narrativa identitaria de una nación expresada a través de una las instancias discursivas y, por lo mismo, culturales, privilegiadas en la construcción de dicha identidad: la literatura. Más aun, la novela, si se toma en cuenta el papel de ese género discursivo en el diseño cultural de las nacientes repúblicas latinoamericanas, semieuropeas por raza y europeizadas por formación y privilegio. Sociedades complacidas en la propagación del modelo europeo de orden y de civilización, atraídas por la proliferación de los héroes entrópicos proyectados por el complejo, traumático y sangriento proceso; pero a la vez culposas y finalmente protectoras de los patrones de libertad vigilada y de los héroes dóciles para ese espacio vigilado.

\section{REFERENCIAS}

Araya, Guillermo. (1975). El amor y la revolución en Martín Rivas. Bulletin Hispanique, 77, 1-2, 3-33.

Barthes, Roland. (1972). El efecto de realidad. En Roland Barthes, MarieClaire Boons, Olivier Burgelin, Jules Gritti, Julia Kristeva, Christian Metz y Tzvetan Todorov (eds.) Lo verosimil (pp. 95-101). Buenos Aires. Editorial Tiempo Contemporáneo.

Beristáin, Helena. (1995). Diccionario de Retórica y Poética. México, D.F.: Porrúa.

Blest Gana, Alberto. (1970). El ideal de un Calavera. En Obras selectas, Tomo I. Buenos Aires, Lima, Río de Janeiro, Caracas, Montevideo, México, Barcelona: Librería El Ateneo Editorial. . (1977). Martín Rivas. Caracas: Biblioteca Ayacucho.

Concha, Jaime. (1972). Martín Rivas o la formación del burgués. Revista Chilena de Literatura, 5-6, 9-36. . (1977). Prólogo. En Martín Rivas (pp. ix-xxxix). Caracas. Biblioteca Ayacucho.

Délano, Luis Enrique. (1968). El padre de la novela chilena. Última Hora, 28 de agosto, s/n. [en línea] Disponible en http://www.memoriachilena. cl/602/w3-article-69002.html. Consulta: 23.09.2013.

Díaz Arrieta, Hernán. (1970). Obras selectas de Blest Gana. Tomo I. Buenos Aires, Lima, Río de Janeiro, Caracas, Montevideo, México, Barcelona: Librería El Ateneo Editorial. 
Drago, Gonzalo. (1980). Alberto Blest Gana, padre de la novela chilena. Las Últimas Noticias, 9 de noviembre, pág. 19.

Foucault, Michel. (1988). Vigilar y castigar. Nacimiento de la prisión. México, D.F.: Siglo XXI.

Gotschlich Reyes, Guillermo. (1987). Grotesco y tragicomedia en 'El ideal de un calavera' de Alberto Blest Gana. Revista Chilena de Literatura, 29, 119-148.

Hosiasson, Laura Janina. (2009). Blest Gana, Martín y el Calavera. Revista Chilena de Literatura, 75, 259-269.

Lotman, Iuri. (1982 [1970]). Estructura del texto artístico. Madrid: Ediciones Istmo.

Lukács, G. (1966 [1936]). Problemas del Realismo. México: F.C.E.

Oyanedel, Marcela. (2005). Lo descriptivo en informes escritos de estudiantes universitarios. Onomázein, 1, 11, 9-21.

Pimentel, Luz Aurora. (2001). El espacio en la ficción. Ficciones espaciales. La representación del espacio en los textos narrativos. Buenos Aires, México: Siglo XXI Editores.

. (2010). El relato en perspectiva. Estudio de teoría narrativa. Buenos Aires, México: Siglo XXI Editores.

Poblete, Juan. (1999). La construcción social de la lectura y la novela nacional: El caso chileno. Latin American Research Review, 34, 2, 75-108.

. (2000). Lectura de la sociabilidad y sociabilidad de la lectura: La novela y las costumbres nacionales en el siglo XIX. Revista de Crítica Literaria Latinoamericana, 26, 52, 11-34.

Riffaterre, Michael. (1981). Descriptive imagery. Yale French Studies, 61, 107-125.

Rodríguez, M. y G. Triviños (eds.). (2006). Utopía y mentira de la novela panóptica. Concepción: Editorial Universidad de Concepción.

Soto, Román. (1992). Continuidad y cambio: Ensayos sobre el héroe en la novela chilena (1861-1951). Nueva York, Santiago de Chile: Ediciones Maitén \& Departamento de Estudios Humanísticos, Facultad de Ciencias Físicas y Matemáticas Universidad de Chile.

Starobinski, Jean. (1981). Brève histoire de la conscience du corps. Revue Française de Psychanalyse, 45, 2, 261-280.

(1989 [1961, 1970]). The living eye. Cambridge, Massachusetts, London, England: Harvard University Press.

. (1991). Entrevista a Jean Starobinski por Carmelo Colangelo. Vuelta 171. [en línea] Disponible en http://www.ddooss.org/articulos/entrevistas/Jean_Starobinski.htm. Consulta: 23.09.2013. 
Subercaseaux, Bernardo. (1980). Nacionalismo literario, realismo y novela en Chile (1850-1860). Revista de Crítica Literaria Latinoamericana, 5, 9, 21-32.

Villanueva, Darío. (2004). Teorías del realismo literario. Madrid: Editorial Biblioteca Nueva. 